\title{
Culture shapes a mesolimbic response to signals of dominance and subordination that associates with behavior
}

\author{
Jonathan B. Freeman ${ }^{\mathrm{a}, *}$, Nicholas O. Rule ${ }^{\mathrm{a}}$, Reginald B. Adams Jr. ${ }^{\mathrm{b}}$, Nalini Ambady ${ }^{\mathrm{a}}$ \\ a Department of Psychology, Tufts University, 490 Boston Avenue, Medford, MA 02155, USA \\ b Department of Psychology, The Pennsylvania State University, 544 Moore Building, University Park, PA 16802, USA
}

\section{A R T I C L E I N F O}

\section{Article history:}

Received 25 September 2008

Revised 8 January 2009

Accepted 8 April 2009

Available online 17 April 2009

\begin{abstract}
A B S T R A C T
It has long been understood that culture shapes individuals' behavior, but how this is accomplished in the human brain has remained largely unknown. To examine this, we made use of a well-established crosscultural difference in behavior: American culture tends to reinforce dominant behavior whereas, conversely, Japanese culture tends to reinforce subordinate behavior. In 17 Americans and 17 Japanese individuals, we assessed behavioral tendencies towards dominance versus subordination and measured neural responses using fMRI during the passive viewing of stimuli related to dominance and subordination. In Americans, dominant stimuli selectively engaged the caudate nucleus, bilaterally, and the medial prefrontal cortex ( $\mathrm{mPFC})$, whereas these were selectively engaged by subordinate stimuli in Japanese. Correspondingly, Americans self-reported a tendency towards more dominant behavior whereas Japanese self-reported a tendency towards more subordinate behavior. Moreover, activity in the right caudate and mPFC correlated with behavioral tendencies towards dominance versus subordination, such that stronger responses in the caudate and mPFC to dominant stimuli were associated with more dominant behavior and stronger responses in the caudate and $\mathrm{MPFC}$ to subordinate stimuli were associated with more subordinate behavior. The findings provide a first demonstration that culture can flexibly shape functional activity in the mesolimbic reward system, which in turn may guide behavior.
\end{abstract}

(c) 2009 Elsevier Inc. All rights reserved.

\section{Introduction}

Humans are no exception to the many social species that are organized by status and hierarchy. One way humans communicate their relative status to others is by producing signals of dominance (indicating higher status) or subordination (indicating lower status). Who dominates and who subordinates is no trivial matter, often determining resource access, aggression, and other outcomes (e.g., de Wall, 1986; Nyquist and Spence, 1986). Given how consequential others' relative status is, it is not surprising that the human perceptual system adapted to sensitively pick up on the various nonverbal signals that convey others' dominance or subordination. These are effortlessly conveyed by bodily expressions (e.g., space, posture), and such signals powerfully shape social interaction and carry important behavioral consequences (Hall et al., 2005).

Though displays of social dominance are often thought to powerfully compel perceivers' attention (Deaner et al., 2005; Maner et al., 2008), a sometimes overlooked aspect of these displays is their reward value to perceivers. Dominant individuals are considered socially attractive and are liked more than lower-status individuals (Hawley, 1999). Neurophysiological work in nonhuman primates points to a

\footnotetext{
* Corresponding author. 490 Boston Avenue, Medford, MA 02155, USA. Fax: + 16176273181 E-mail address: jon.freeman@tufts.edu (J.B. Freeman).
}

special role of dopaminergic reward circuitry in the expression of social dominance (Kaplan et al., 2002) and, in humans, arbitrary visual stimuli that are connotative of social dominance (i.e., sports cars and luxury cars) activate this reward circuitry (Erk et al., 2002). It is thus not surprising that evolutionary theorists postulate the recognition of social dominance displays to be positively rewarding (Hawley, 1999).

Though the perception of dominance and subordination displays is undeniably related to distal evolutionary challenges (Hawley, 1999), it may be possible that more proximal mechanisms in humans, such as cultural learning, could potently shape perceivers' experience of these displays. In the United States, individuals' dominant behavior is positively reinforced; Americans are encouraged to be independent, self-elevating, and assertive (e.g., Moskowitz et al., 1994). Theorized to be due to high competitiveness in American culture, individuals are generally taught to dominate and climb the hierarchy (Triandis and Gelfand, 1998). Thus, in the United States, stimuli signaling social dominance-even arbitrary images (e.g., sports cars)-are likely to be positively rewarding. Indeed, this is consistent with extant work using American participants (e.g., Erk et al., 2002; Marsh et al., in press). However, although there is high consistency in the cues signaling dominance and subordination across cultures (Bridge et al., 2007), not every culture assigns value to these cues in the same way. Quite different from the United States, in Japan (a collectivist and allocentric society; Triandis and Suh, 2002) subordination, sociability, and 
cooperation-not dominance-tend to be positively reinforced (Triandis and Gelfand, 1998). Japanese society typically encourages individuals to be agreeable rather than dominant (Moskowitz et al., 1994; Realo et al., 1997) and affiliative rather than competitive (Yamaguchi et al., 1995). Allocentric cultures, such as Japan's, stress the importance of appearing to others as responsive to their needs and concerns (Cross et al., 2000) and to feel a sense of obligation to them (Oyserman et al., 1998). For instance, in Japanese culture, the quintessential hero is often characterized as one that possesses unassailable strength (similar to in American culture) but, more importantly, is one that maintains a profound humility and readily displays vulnerability (de Mente, 2006). Because in Japan appearing subordinate to others tends to be positively reinforced, for Japanese individuals, stimuli signaling subordination-not dominance-are likely to be positively rewarding (Nakane, 1970; Rosenberger, 1995).

Given this cross-cultural difference in the valuation of dominance and subordination, we investigated whether this difference in culturally learned reward assignments would manifest as different patterns of functional activity in the neural mechanisms responsible for processing these. Researchers have long understood that human culture powerfully shapes individuals' behavior, but only recently have they begun to examine how culture influences the functioning of the neural systems underlying it (Chiao and Ambady, 2007; Han and Northoff, 2008). It is currently unknown whether culture can shape responses in primary reward mechanisms of the human brain. Considering that these mechanisms are at the seat of human motivation, decision-making, and behavior (Schultz, 2000), it is important to test whether they could be constrained by the highorder influences of human culture. Here we investigate whether culture can shape responses in primary reward mechanisms of the human brain, which in turn associate with behavior.

A growing body of neuroimaging research on mesolimbic reward circuitry has demonstrated that this circuitry not only responds to primary reinforcers such as food and sex but also to more abstract cognitive rewards (i.e., "secondary" reinforcers that come to take on motivational significance through learning; Schultz, 2000), such as money, attractive faces, and symbols of status (e.g., Aharon et al., 2001; Breiter et al., 2001). Moreover, recent studies have implicated this same mesolimbic circuitry in processing the learned reward value of even complex social stimuli or phenomena (see Knutson and Wimmer, 2007 for review). For instance, during social interaction, this circuitry shows increased activity in response to cooperation (Rilling et al., 2002) and revenge (de Quervain et al., 2004). Moreover, the caudate nucleus, a key player in the mesolimbic reward system, exhibits patterns of activity that reflect updates about another's social reputation and trustworthiness during two-person interactive economic exchange (King-Casas et al., 2005). Although such studies show that humans are capable of flexibly learning to assign reward value to novel and complex social stimuli, and that the mesolimbic dopamine system classically understood as processing unlearned primary rewards similarly processes these learned secondary social rewards, it still remains unknown whether reward-related mesolimbic activity may be shaped by high-level cultural learning. Here we use a difference in culturally reinforced behaviors (dominance and subordination in Japan and the United States) to examine cultural influences on reward and related behavior in the human brain.

Event-related functional magnetic resonance imaging (fMRI) was used to measure blood oxygenation-level-dependent (BOLD) signals in individuals from Japan and individuals from the United States while they viewed visual stimuli related to dominance and subordination. Given that American culture positively reinforces dominance whereas Japanese culture positively reinforces subordination, we hypothesized that Americans would show stronger reward-related mesolimbic activity to dominant stimuli relative to subordinate, whereas Japanese individuals would show the reverse pattern: stronger reward-related mesolimbic activity to subordinate stimuli relative to dominant.
Additionally, if these two cultures indeed differentially reinforce dominance and subordination, we should expect to see a difference between Americans and Japanese in actual self-reported behavioral tendencies towards dominance and subordination (i.e., Americans should be more inclined towards dominant behavior and Japanese more inclined towards subordinate behavior). Lastly, given that the mesolimbic dopamine system activates in response to reinforcers ultimately for motivating and commanding behavior (Arias-Carrión and Pöppel, 2007; Schultz, 2000), we tested whether mesolimbic BOLD responses to signals of dominance and subordination could predict individual differences in behavioral tendencies towards dominance versus subordination. Taken together, such findings would reveal that culture can shape the basic neural mechanisms underlying reward, which in turn relate to human behavior.

\section{Materials and methods}

\section{Participants}

Seventeen right-handed healthy volunteers born and raised in the United States ( 8 male) and 17 right-handed healthy volunteers born and raised in Japan ( 8 male) participated in the study. All participants gave informed consent in a manner approved by the Massachusetts Institute of Technology's Committee On the Use of Humans as Experimental Subjects and were paid for their participation. Both Americans and Japanese were scanned at the Athinoula A. Martinos Center for Biomedical Imaging in Cambridge, MA. At the time of scanning, Japanese participants were residing in the United States for approximately one month in completion of a study abroad program hosted by Tufts University. All Japanese participants were born in Japan and were lifetime residents of Japan; all American participants were born in the United States and were lifetime residents of the United States.

\section{Behavioral procedure}

Stimuli included 36 dominant displays, 36 subordinate displays, and 36 random displays of the body unrelated to dominance or subordination (used as fillers to reduce participants' awareness of the research question). Body displays were photographs of 5 male actors, converted into figural outlines (so as to preserve only nonverbal information about dominance/subordination and remove cultural membership cues; e.g., Ambady et al., 2000) and placed onto a white background (see Fig. 1), consistent with previous research (see Hall et al., 2005). Stimuli and an additional 36 baseline trials (fixation cross) were passively viewed each for $2 \mathrm{~s}$ in one of three pseudorandomized orders, each sequenced in a manner as to maximize the efficiency of eventrelated BOLD signal estimation (Dale, 1999).

Following the fMRI task, participants completed a questionnaire, adapted from Goldberg et al.'s (2006) International Personality Item Pool, which indexed behavioral tendencies of dominance versus subordination. Participants were asked to indicate how accurately ( 1 - "very inaccurate" to 5 - "very accurate") 15 statements described their behavior (e.g., "I impose my will on others"; "I let others make the decisions"). See Table 1 for a list of all statements. Subordinate statements, such as the latter example, were reverse coded, and subtracted by a constant of 3 such that negative scores indicate a tendency towards subordination and positive scores indicate a tendency towards dominance.

\section{fMRI acquisition}

Participants were scanned using a Siemens $3 \mathrm{~T}$ Tim Trio scanner at the Massachusetts Institute of Technology, Martinos Imaging Center. Anatomical images were acquired using a T1-weighted protocol ( $256 \times 256$ matrix, 128 1.33-mm sagittal slices). Functional images were acquired using a single-shot gradient echo EPI sequence 
A

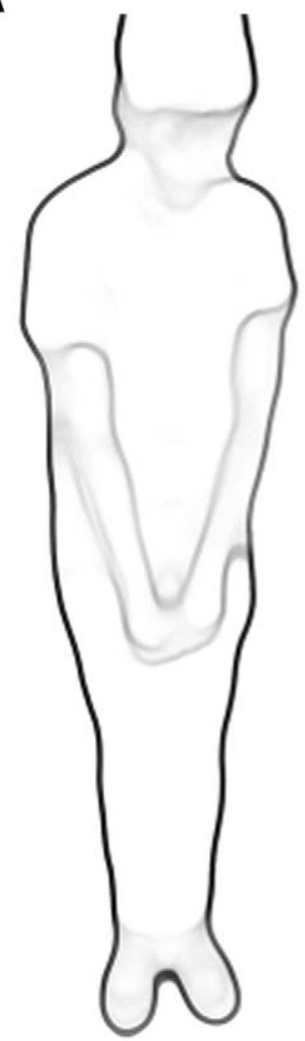

B

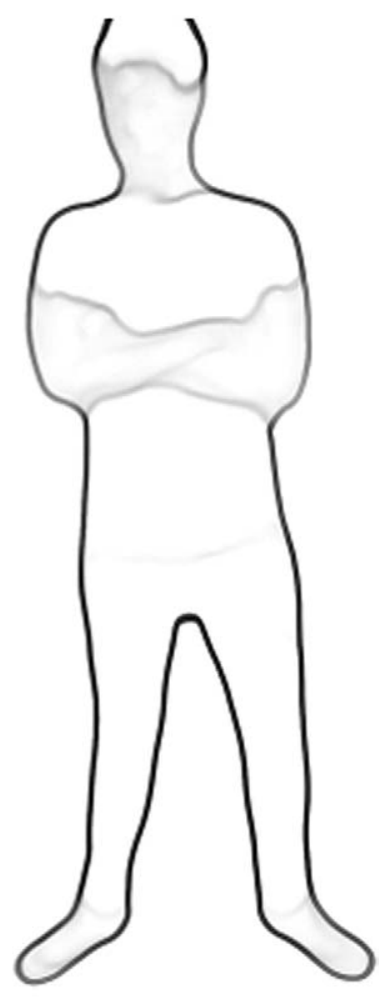

Fig. 1. Examples of a (A) subordinate display and a (B) dominant display, consistent with previous research (Ambady et al., 2000; Hall et al., 2005).

$(\mathrm{TR}=2000 \mathrm{~ms}, \mathrm{TE}=30 \mathrm{~ms})$. Thirty-two interleaved oblique-axial slices $(3.125 \times 3.125 \times 5 \mathrm{~mm}$ voxels; slice gap $=1 \mathrm{~mm})$ parallel to the $\mathrm{AC}-\mathrm{PC}$ line were obtained. Analysis of the imaging data was conducted using BrainVoyagerQX (Brain Innovation, Maastricht, Netherlands). Functional imaging data preprocessing included 3D motion correction, slice scan time correction (sinc interpolation), spatial smoothing using a 3D Gaussian filter (7-mm FWHM), and voxelwise linear detrending and high-pass filtering of frequencies (above 3 cycles per time course). Structural and functional data of each participant were transformed to standard Talairach stereotaxic space (Talairach and Tournoux, 1988).

\section{fMRI analysis}

Each participant's BOLD signals corresponding with individual conditions were modeled in an event-related design as boxcar functions convolved with a two-gamma hemodynamic response function. Firstlevel general linear model (GLM) analyses conducted on individual participants' fMRI signal were submitted to a second-level random effects analysis, treating participants as a random factor. For group-level whole-brain analyses, we controlled for multiple statistical testing of voxels within the entire brain, maintaining a false positive detection rate of $p<.001$ by using a voxelwise threshold of $p<.001$ and a minimum cluster size of $189 \mathrm{~mm}^{3}$. The minimum cluster size needed to maintain the false positive detection rate was empirically determined by a Monte Carlo simulation, accounting for spatial correlations in BOLD signal changes of neighboring voxels (Forman et al., 1995). Statistical maps depicting BOLD responses were overlaid onto an average image of all participants' corresponding structural data.

\section{Results}

Given that American culture and Japanese culture are believed to differentially reinforce dominance and subordination, respectively, we

expected American and Japanese participants to show a corresponding difference in actual behavioral tendencies towards these. As anticipated, self-reported behavioral tendencies towards dominance and subordination significantly differed between Americans and Japanese, $t(32)=2.04, p<.05$ (two-tailed test). Specifically, Americans reported a tendency towards more dominant behavior $(M=.29$, $S E=.14)$, whereas Japanese reported a tendency towards more subordinate behavior $(M=-.14, S E=.16)$. Means and standard errors for each questionnaire item, separately for the two cultures, appear in Table 1.

Although not directly related to the primary research question, we initially determined whether any brain regions showed stronger responses to dominant displays relative to subordinate displays, regardless of culture, by conducting a dominant $>$ subordinate contrast using a whole-brain analysis ( $p<.001$, corrected). This analysis revealed activity in the left inferior parietal lobule (IPL; $x, y, z=-48,-37,46$, $520 \mathrm{~mm}^{3}, t=4.77$ ) and in the bilateral lingual gyri (right: $x, y, z=17$, $-91,22,1052 \mathrm{~mm}^{3}, t=4.83$; left: $x, y, z=-12,-93,15,2896 \mathrm{~mm}^{3}$, $t=5.24$ ). When threshold was slightly relaxed (voxelwise $p<.005$; minimum cluster size $\left.>250 \mathrm{~mm}^{3}\right)$, the right IPL $(x, y, z=42,-36,51$, $\left.1489 \mathrm{~mm}^{3}, t=3.88\right)$ and a ventral aspect of the medial prefrontal cortex (mPFC; ventral BA $10 ; x, y, z=-14,52,-1,291 \mathrm{~mm}^{3}, t=3.55$ ) additionally emerged. This pattern of activity is consistent with previous research on the perception of status cues from the human face (Karafin et al., 2004; Marsh et al., in press). We used the inverse contrast (subordinate>dominant) to assess whether any regions showed stronger responses to subordinate displays relative to dominant, regardless of culture $(p<.001$, corrected). This analysis revealed no regions of activation that survived correction.

To assess the primary hypothesis-that Americans and Japanese would exhibit opposite patterns of a reward-related response to precisely the same signals of dominance and subordination-we conducted a whole-brain mixed-model analysis of variance (ANOVA), testing a status display (dominant, subordination) $\times$ culture (Japanese, American) interaction effect $(p<.001$, corrected). This revealed robust activity in the head of the caudate nucleus, bilaterally (right: $x$, $y, z=7,17,8,845 \mathrm{~mm}^{3}, F=30.99$; left: $x, y, z=-11,-18,5$, $677 \mathrm{~mm}^{3}, F=20.54$ ) and in a dorsal aspect of the mPFC (dorsal BA 10; $\left.x, y, z=8,59,23,196 \mathrm{~mm}^{3}, F=17.14\right)$. To specify the nature of this interaction, parameter estimates (beta values) for each of the conditions (dominant and subordinate) were extracted from all

Table 1

Questionnaire items indexing behavioral tendencies towards dominance versus subordination, adapted from Goldberg et al.'s (2006) International Personality Item Pool.

\begin{tabular}{|c|c|c|c|c|}
\hline \multirow[t]{2}{*}{ Statement } & \multicolumn{2}{|c|}{ Japanese } & \multicolumn{2}{|c|}{ Americans } \\
\hline & $\bar{M}$ & $S E$ & $\bar{M}$ & SE \\
\hline \multicolumn{5}{|l|}{ Dominant } \\
\hline I try to surpass others' accomplishments. & 3.82 & 0.26 & 3.88 & 0.22 \\
\hline I want to control the conversation. & 2.41 & 0.29 & 2.47 & 0.23 \\
\hline I am not afraid of providing criticism. & 2.76 & 0.33 & 3.29 & 0.33 \\
\hline I challenge others' points of view. & 3.00 & 0.32 & 3.65 & 0.21 \\
\hline I lay down the law to others. & 2.12 & 0.21 & 2.18 & 0.26 \\
\hline I put people under pressure. & 1.76 & 0.22 & 2.24 & 0.22 \\
\hline I impose my will on others. & 2.29 & 0.29 & 2.18 & 0.25 \\
\hline I express myself easily. & 3.18 & 0.27 & 3.65 & 0.30 \\
\hline I try to lead others. & 2.94 & 0.33 & 3.59 & 0.24 \\
\hline I am the first to act. & 3.12 & 0.35 & 3.53 & 0.26 \\
\hline I take control of things. & 2.71 & 0.25 & 3.29 & 0.27 \\
\hline \multicolumn{5}{|l|}{ Subordinate } \\
\hline I wait for others to lead the way. & 3.00 & 0.28 & 2.53 & 0.31 \\
\hline I let others make the decisions. & 2.94 & 0.20 & 2.82 & 0.26 \\
\hline I am not highly motivated to succeed. & 2.29 & 0.36 & 1.53 & 0.26 \\
\hline I can't come up with new ideas. & 3.00 & 0.30 & 1.65 & 0.23 \\
\hline
\end{tabular}

Means and standard errors are presented as original scores: $1=$ "very inaccurate" and $5=$ "very accurate." 
voxels within each of these regions (Fig. 2). In Americans, these regions showed significantly stronger BOLD responses to dominant displays relative to subordinate displays: left caudate $[t(16)=3.93$, $p=.001$ (two-tailed)], right caudate $[t(16)=3.51, p<.01$ (twotailed)], $\operatorname{mPFC}[t(16)=2.53, p<.05$ (two-tailed)]. However, in Japanese, these same regions showed the reverse pattern, exhibiting significantly stronger BOLD responses to subordinate displays relative to dominant displays: left caudate $[t(16)=3.50, p<.01$ (two-tailed)], right caudate $[t(16)=5.12, p=.0001$ (two-tailed)], $\mathrm{mPFC}[t(16)=3.57$, $p<.01$ (two-tailed)]. Thus, Americans exhibited stronger mesolimbic reward-related activity to dominant displays, whereas Japanese-in response to the very same stimuli-exhibited stronger mesolimbic activity to subordinate displays.

Finally, to determine whether these mesolimbic responses to dominant and subordinate displays were related to participants' actual tendencies towards dominant or subordinate behavior, we first calculated BOLD signal difference scores [dominant - subordinate] by subtracting beta values for the subordinate condition from beta values for the dominant condition, separately for each participant. Thus, positive scores indicate stronger responses to dominant displays whereas negative scores indicate stronger responses to subordinate displays. We then examined the relationship between these difference scores and participants' reported behavioral tendencies towards dominance/subordination. Indeed, [dominant - subordinate] BOLD signal difference scores significantly correlated with participants' selfreported behavioral tendencies towards dominance or subordination: right caudate $[r(32)=.34, p<.05$ (two-tailed) ], $\operatorname{mPFC}[r(32)=.44$, $p<.01$ (two-tailed)], and a similar positive trend in the left caudate that did not reach significance $[r(32)=.16, p=n . s$. (two-tailed)] (Fig. 3). Thus, the stronger the BOLD responses in the caudate and
mPFC were to dominant stimuli, the more dominant participants reported their behavior to be; the stronger the BOLD responses in the caudate and MPFC were to subordinate stimuli, the more subordinate participants reported their behavior to be.

\section{Discussion}

Here we found that when American and Japanese participants perceived identical signals of dominance and subordination, in Americans, the caudate and MPFC showed selective responses to dominant stimuli, whereas, conversely, in Japanese, these same regions showed selective responses to subordinate stimuli. Complementing this, Americans reported a tendency towards more dominant behavior whereas Japanese individuals reported a tendency towards more subordinate behavior. Moreover, BOLD signals in the caudate and mPFC correlated with reported dominant/subordinate behavioral tendencies, such that participants exhibiting greater activation for dominant stimuli exhibited a greater tendency towards more dominant behavior whereas participants exhibiting greater activation for subordinate stimuli exhibited a greater tendency towards more subordinate behavior. Taken together, these results provide a first demonstration that human culture can compel patterns of functional activity in mesolimbic reward circuitry, which in turn associates with behavior.

The head of the caudate nucleus has long been implicated in reward-related processing across species, specifically in reward detection and the associative learning of rewards (Balleine et al., 2007; Graybiel, 2005; Williams and Eskandar, 2006). It is sensitive to a variety of motivationally significant stimuli, both positively rewarding and negatively aversive (Graybiel, 2005), and, consistent with the

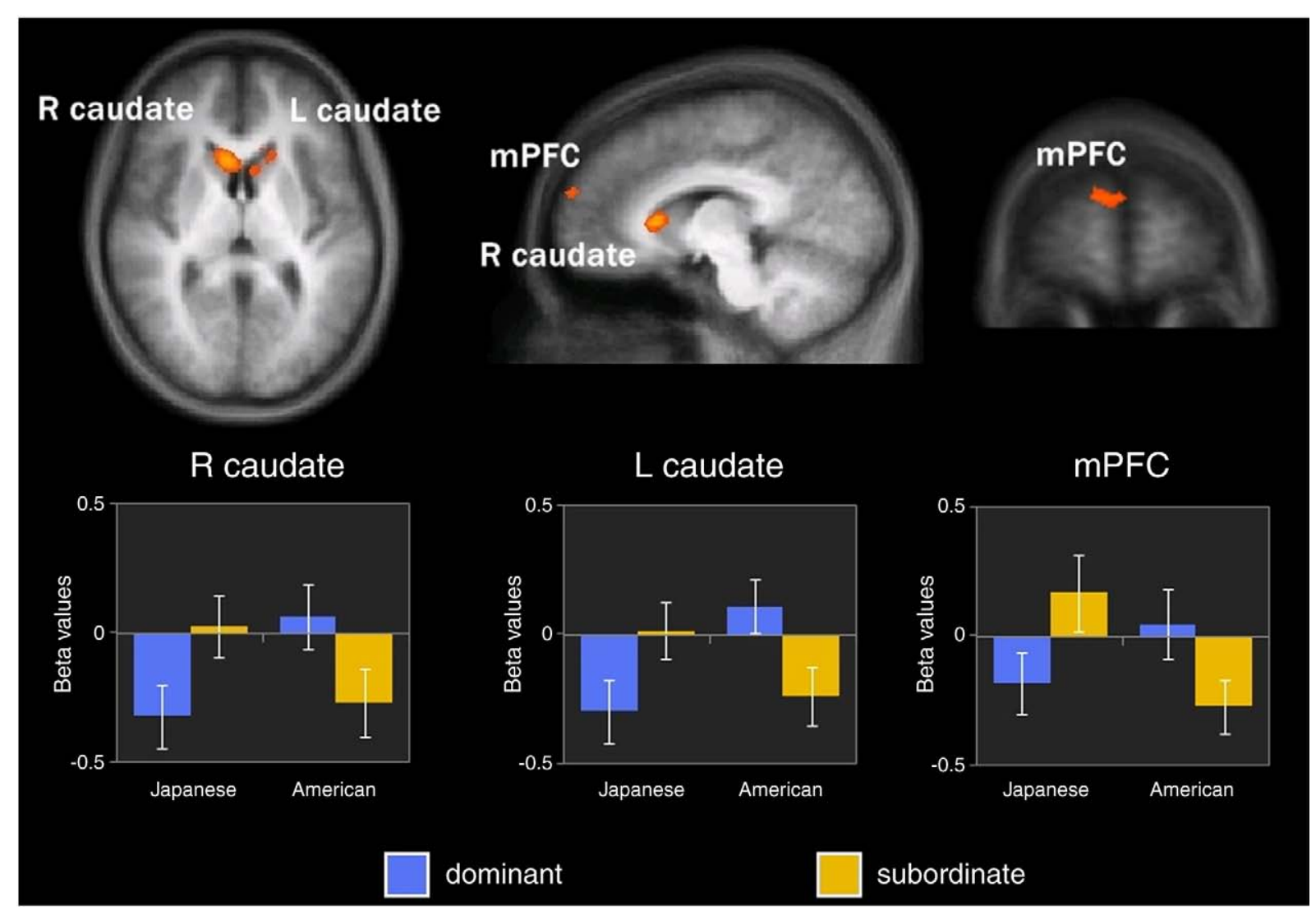

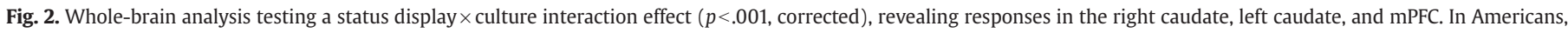

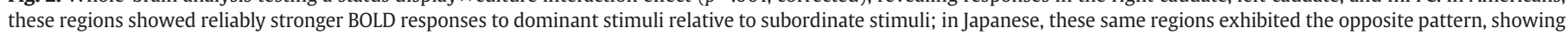
reliably stronger BOLD responses to subordinate stimuli relative to dominant stimuli. 
Japanese

Americans

A

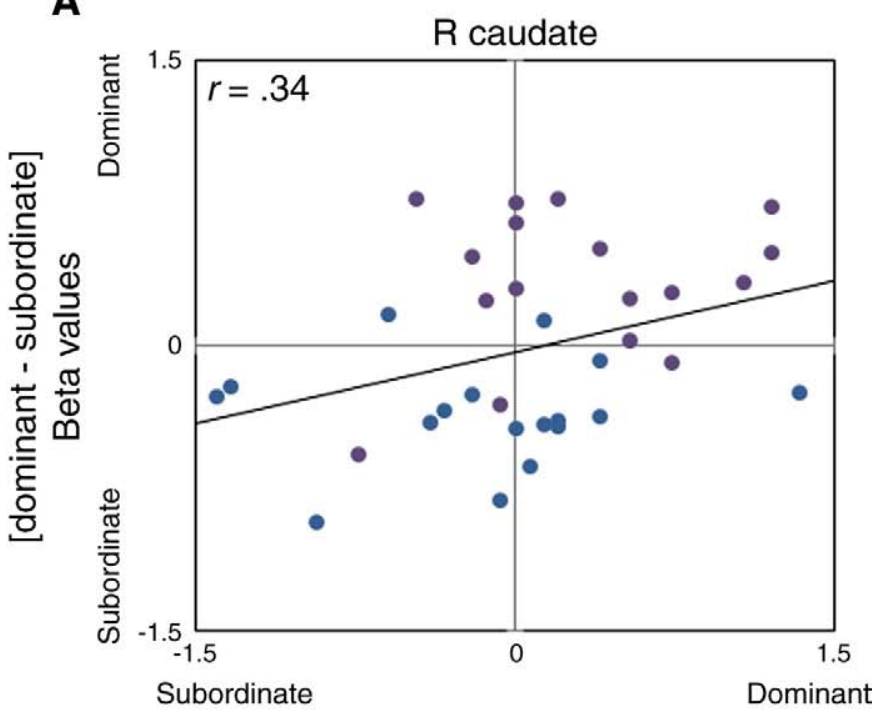

Behavioral tendency

\section{B}

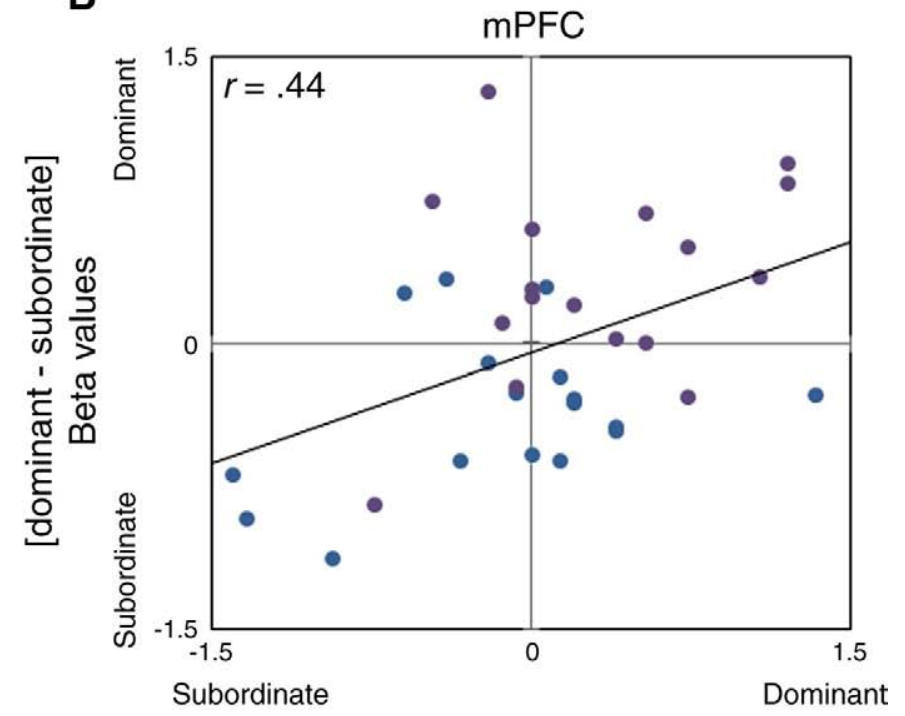

Behavioral tendency

Fig. 3. Correlations between participants' self-reported behavioral tendencies towards dominance/subordination and BOLD responses revealed by the whole-brain analysis testing a status display $\times$ culture interaction effect. There was a statistically significant correlation between behavioral tendencies of dominance/subordination and [dominant subordinate] BOLD signal difference scores from the (A) right caudate and (B) MPFC. BOLD signal difference scores were calculated by subtracting beta values for the subordinate condition from beta values for the dominant condition, separately for each participant. Thus, the stronger the responses were in the right caudate and mPFC to dominant stimuli, the more dominant participants reported their behavior to be; the stronger the responses were in the right caudate and MPFC to subordinate stimuli, the more subordinate participants reported their behavior to be.

present findings, activity in the caudate nucleus can predict rewardoriented behavior in nonhuman primates (e.g., Itoh et al., 2003). Recent evidence has set apart the caudate from the larger mesolimbic reward system for its specific involvement in action-contingency learning through reward-prediction error coding (Delgado et al., 2005; O'Doherty et al., 2004; Tricomi et al., 2004). Such evidence suggests that a primary role of the caudate nucleus is associating behaviors with their reward consequences. Given that the caudate can flexibly associate behaviors with their reward value and, as described earlier, can process the learned reward values of complex social phenomena such as cooperation (Rilling et al., 2002), revenge (de Quervain et al., 2004), and social reputation and trust during interactive economic exchange (King-Casas et al., 2005), it is fitting that here we find that caudate responses can be flexibly shaped by human culture and correlated with social behavior (behavioral tendencies of dominance and subordination). Taken together with prior studies of the caudate's role in learning behavior-reward associations and processing the learned reward value of complex social phenomena, the present findings point to the caudate as a critical player in shaping culturally-specific human behavior by linking the associations between particular behaviors (e.g., dominance and subordination) and their cultural reward value.

The mPFC (BA 10) has also been consistently implicated in rewardrelated processing across species (Tzschentke, 2000; Wise, 2005) and carries the densest dopaminergic input in the cortex, making it a key player in mesolimbic reward circuitry (Tzschentke, 2000). It is connected to the caudate and encompassing striatum via mesocorticolimbic projections and, like the striatum, the MPFC has also been shown to respond to learned secondary reinforcers. For instance, relative to normals, the $\mathrm{mPFC}$ in alcoholics shows stronger responses to alcohol-related visual stimuli in a way that associates with drugseeking behavior (i.e., obtaining alcohol; Grüsser et al., 2004), a finding somewhat analogous to that reported here. Beyond its role in monitoring rewards (Thut et al., 1997), several neuroimaging studies point to the mPFC's involvement in representations of the self (e.g., Kelley et al., 2002) and sentiments related to social and moral values (Moll et al., 2008). These studies suggest that the pattern of mPFC responses found here may relate not to the detection or monitoring of the reward per se, but to a retrieval or representation of self-relevant cultural values (i.e., for Americans, the value of the self as dominant; for Japanese, the value of the self as subordinate), which in turn may guide the caudate's reward-related response that is associated with behavior. Future research could further characterize the particular role of the MPFC in culture-bound reward and related behavior.

Converging with prior studies using American participants (Karafin et al., 2004; Marsh et al., in press), here we found that a ventral aspect of the mPFC was selectively engaged by dominant stimuli, regardless of culture. Researchers have previously suggested that the selective involvement of this ventral mPFC region in responding to cues of dominance is likely related to reward representation (Marsh et al., in press). This highlights a dissociation in the $\mathrm{mPFC}$ between a more ventral region showing stronger responses to dominant stimuli relative to subordinate stimuli, irrespective of culture, and a more dorsal region showing stronger responses to either dominant stimuli or subordinate stimuli, dependent on whichever is culturally reinforced. The present findings thus demonstrate that although both the ventral and dorsal MPFC are involved in a reward-related response to status cues, the ventral aspect appears to be insensitive to cultural learning (showing a culture-independent increase in activity for dominant cues) whereas the dorsal aspect is indeed shaped by cultural learning (showing a culture-dependent increase in activity for whichever status cue is positively reinforced).

Some readers may be concerned by the possibility that the reported caudate and dorsal $\mathrm{mPFC}$ responses might reflect merely an effect of visual attention: that dominant and subordinate displays captured attention differently in Americans and Japanese. If such were the case, however, brain areas associated with enhanced visual attention (namely, striate and extrastriate regions) should have emerged in the whole-brain analysis testing a status display $\times$ culture interaction effect. Inconsistent with this, we found that characteristic areas of enhanced visual processing, including the bilateral lingual gyri (Kastner and Ungerleider, 2000) and the bilateral IPL, an area involved in representing displays of the human body including their intention (Decety et al., 1994; Stephan et al., 1995), showed stronger 
responses to dominant displays relative to subordinate displays, consistently across both Americans and Japanese. This converges with evidence demonstrating that dominant displays selectively compel perceivers' attention (Deaner et al., 2005; Maner et al., 2008). Because regions characteristic of enhanced visual attention were activated by dominant stimuli similarly in both cultures and because the caudate head and dorsal mPFC are not regions generally implicated in the deployment of visual attention (Kastner and Ungerleider, 2000), it is unlikely that the reported caudate and dorsal mPFC responses were due to an effect of Americans and Japanese differentially attending to dominant and subordinate stimuli.

It is important to note that although much research in cultural psychology and social anthropology has identified clear macrocosmic differences between American and Japanese culture in their orientations towards dominance and subordination (e.g., Nakane, 1970; Rosenberger, 1995; Triandis and Suh, 2002), described earlier, we do not wish to imply that these orientations are universal or homogeneous within a particular culture, and we caution readers from making such an interpretation. Culture is highly complex and filled with heterogeneity (cf. Ratner, 1997). By no means do we wish to suggest that dominance is rewarding for every American and subordination rewarding for every Japanese individual, nor that all Americans are inclined towards more dominant behavior and all Japanese inclined towards more subordinate behavior. As often is the case in the behavioral sciences, when two groups reliably differ from one another, these differences are usually understood most meaningfully at the group level, and underlying these differences is often a rich diversity among individuals. The same principle holds true for differences between two cultures. Also important to note is that although the term subordination, for Western readers, may connote a sense of defeat and be construed very unfavorably, this is not necessarily implied in Japanese culture. Although many Westerners likely assume differently based on the lens of their own culture, subordination in Japan is generally construed positively, understood as a prosperous and productive route that engenders cooperation and affiliation, and without any negative connotation or sense of defeat (cf. Nakane, 1970).

In summary, here we have shown that culture shapes a mesolimbic response to signals of dominance and subordination, and this response associates with a cross-cultural difference in self-reported behavior.

\section{Acknowledgments}

We thank Martin Maguire and Natan Magid for assisting in data collection and Peter Sokol-Hessner for comments on an earlier version of this manuscript. This study was funded by a National Science Foundation grant \# 0724416 to NA.

\section{References}

Aharon, I., Etcoff, N., Ariely, D., Chabris, C., O'Connor, E., Breiter, H., 2001. Beautiful faces have variable reward value fMRI and behavioral evidence. Neuron 32, 537-551.

Ambady, N., Bernieri, J.F., Richeson, J.A., 2000. Toward a histology of social behavior: judgmental accuracy from thin slices of the behavioral stream. In: Zanna, M.P. (Ed.), Advances in Experimental Social Psychology. Academic Press, San Diego, pp. 201-272.

Arias-Carrión, O., Pöppel, E., 2007. Dopamine, learning, and reward-seeking behavior. Acta Neurobiol. Exp. 67, 481-488.

Balleine, B.W., Delgado, M.R., Hikosaka, O., 2007. The role of the dorsal striatum in reward and decision-making. J. Neurosci. 27, 8161-8165.

Breiter, H.C., Aharon, I., Kahneman, D., Dale, A., Shizgal, P., 2001. Functional imaging of neural responses to expectancy and experience of monetary gains and losses. Neuron 30, 619-639.

Bridge, D., Li, Z., Tsao, M., Chiao, J., 2007. Universality and cultural specificity in social dominance perception: effects of gender and culture on facial judgments. J. Vision 7, 13a.

Chiao, J.Y., Ambady, N., 2007. Cultural neuroscience: parsing universality and diversity across levels of analysis. In: Kitayama, S., Cohen, D. (Eds.), Handbook of Cultural Psychology. Guilford Press, New York, pp. 237-254.
Cross, S.E., Bacon, P., Morris, M., 2000. The relational-interdependent self-construal and relationships. J. Pers. Soc. Psychol. 78, 791-798.

Dale, A.M., 1999. Optimal experimental design for event-related fMRI. Hum. Brain Mapp. 8, 109-114.

Decety, J., Perani, D., Jeannerod, M., Bettinardi, V., Tadary, B., Woods, R., Mazziotta, J.C., Fazio, F., 1994. Mapping motor representation with positron emission tomography Nature 371, 600-601.

De Mente, B.L., 2006. Japan Unmasked: The Character and Culture of the Japanese Tuttle Publishing, Singapore.

de Quervain, D.J.F., Fischbacher, U., Treyer, V., Schellhammer, M., Schnyder, U., Buck, A., Fehr, E., 2004. The neural basis of altruistic punishment. Science 305, 1254-1258.

de Wall, F.B., 1986. The integration of dominance and social bonding in primates. Q. Rev. Biol. 61, 459-479.

Deaner, R.O., Khera, A.V., Platt, M.L., 2005. Monkeys pay per view: adaptive valuation of social images by rhesus monkeys. Curr. Biol. 15, 543-548.

Delgado, M.R., Miller, M.M., Inati, S., Phelps, E.A., 2005. An fMRI study of reward-related probability learning. Neurolmage 24, 862-873.

Erk, S., Spitzer, M., Wunderlich, A.P., Galley, L., Walter, H., 2002. Cultural objects modulate reward circuitry. Neuroreport 13, 2499-2503.

Forman, S.D., Cohen, J.D., Fitzgerald, M., Eddy, W.F., Mintun, M.A., Noll, D.C., 1995 Improved assessment of significant activation in functional magnetic resonance imaging: use of a cluster-size threshold. Magn. Res. Med. 33, 636-647.

Goldberg, L.R., Johnson, J.A., Eber, H.W., Hogan, R., Ashton, M.C., Cloninger, C.R., Gough, H.G., 2006. The international personality item pool and the future of public-domain personality measures. J. Res. Person. 40, 84-96.

Graybiel, A.M., 2005. The basal ganglia: learning new tricks and loving it. Curr. Opin. Neurobiol. 15, 638-644.

Grüsser, S.M., 2004. Cue-induced activation of the striatum and medial prefrontal cortex is associated with subsequent relapse in abstinent alcoholics. Psychopharmacology 175, 296-302.

Hall, J.A., Coats, E.J., LeBeau, L.S., 2005. Nonverbal behavior and the vertical dimension of social relations: a meta-analysis. Psychol. Bull. 131, 898-924.

Han, S., Northoff, G., 2008. Culture-sensitive neural substrates of human cognition: a transcultural neuroimaging approach. Nat. Rev. Neurosci. 9, 646-654.

Hawley, P.H., 1999. The ontogenesis of social dominance: a strategy-based evolutionary perspective. Dev. Rev. 19, 97-132.

Itoh, H., Nakahara, H., Hikosaka, O., Kawagoe, R., Takikawa, Y., Aihara, K., 2003. Correlation of primate caudate neural activity and saccade parameters in rewardoriented behavior. J. Neurophysiol. 89, 1774-1783.

Kaplan, J.R., Manuck, S.B., Fontenot, M.B., Mann, J.J., 2002. Central nervous system monoamine correlates of social dominance in cynomolgus monkeys (Macaca fascicularis). Neuropsychopharmacology 26, 431-443.

Karafin, M.S., Tranel, D., Adolphs, R., 2004. Dominance attributions following damage to the ventromedial prefrontal cortex. J. Cogn. Neurosci. 16, 1796-1804.

Kastner, S., Ungerleider, L.G., 2000. Mechanisms of visual attention in the human cortex Ann. Rev. Neurosci. 23, 315-341.

Kelley, W.M., Macrae, C.N., Wyland, C.L., Caglar, S., Inati, S., Heatherton, T.F., 2002 Finding the self? An event-related fMRI study. J. Cogn. Neurosci. 14, 785-794.

King-Casas, B., Tomlin, D., Anen, C., Camerer, C.F., Quartz, S.R., Montague, P.R., 2005. Getting to know you: reputation and trust in a two-person economic exchange. Science 308, 78-83.

Knutson, B., Wimmer, G.E., 2007. Reward: neural circuitry for social valuation. In: Harmon-Jones, E., Winkielman, P. (Eds.), Social Neuroscience. Guilford Press, New York, pp. 157-175

Maner, J.K., DeWall, C.N., Gailliot, M.T., 2008. Selective attention to signs of success: social dominance and early stage interpersonal perception. Pers. Soc. Psychol. Bull. 34, 488-501.

Marsh, A.A., Blair, K.S., Jones, M.W., Soliman, N., and Blair, R.J.R. (in press). Dominance and submission: the ventromedial prefrontal cortex and responses to status cues. J. Cogn. Neurosci.

Moll, J., de Oliveira-Souza, R., Zahn, R., 2008. The neural basis of moral cognition. Ann. N.Y. Acad. Sci. 1124, 161-180.

Moskowitz, D.S., Suh, E.J., Desaulniers, J., 1994. Situational influences on gender differences in agency and communion. J. Pers. Soc. Psychol. 66, 753-761.

Nakane, C., 1970. Japanese Society. Penguin Books, Middlesex.

Nyquist, L.V., Spence, J.T., 1986. Effects of dispositional dominance and sex role expectations on leadership behaviors. J. Pers. Soc. Psychol. 50, 87-93.

O'Doherty, J., Dayan, P., Schultz, J., Diechmann, R., Friston, K., Dolan, R.J., 2004. Dissociative roles of ventral and dorsal striatum in instrumental conditioning. Science 304, 452-454.

Oyserman, D., Sakamoto, I., Lauffer, A., 1998. Cultural accommodation: hybridity and the framing of social obligation. J. Pers. Psychol. 74, 1606-1618.

Ratner, C., 1997. In defense of activity theory. Cult. Psychol. 3, 211-223.

Realo, A., Allik, J., Vadi, M., 1997. The hierarchical structure of collectivism. J. Res. Pers. 31, 93-116.

Rilling, J., Gutman, D., Zeh, T., Pagmoni, G., Berns, G., Kilts, C., 2002. A neural basis for social cooperation. Neuron 35, 395-405.

Rosenberger, N.R. (Ed.), 1995. Japanese Sense of Self. Cambridge University Press, Cambridge Schultz, W., 2000. Multiple reward signals in the brain. Nat. Rev. Neurosci. 1, 199-207.

Stephan, K.M., Fink, G.R., Passingham, R.E., Silbersweig, D., Caballos-Baumann, A.O., Frith, C.D., Frackowiak, R.S., 1995. Functional anatomy of the mental representation of upper extremity movements in healthy subjects. J. Neurophysiol. 73, 373-386.

Talairach, J., Tournoux, P., 1988. Co-planar Stereotaxic Atlas of the Human Brain. Theme, New York.

Thut, G., Schultz, W., Roelcke, U., Nienhusmeier, M., Missimer, J., Maguire, R.P., Leenders, K.L., 1997. Activation of the human brain by monetary reward. NeuroReport 8 1225-1228. 
Triandis, H.C., Gelfand, M.J., 1998. Converging measurement of horizontal and vertical individualism and collectivism. J. Pers. Soc. Psychol. 74, 118-128.

Triandis, H.C., Suh, E.M., 2002. Cultural influences on personality. Ann. Rev. Psychol. 53, 133-160. Tricomi, E.M., Delgado, M.R., Fiez, J.A., 2004. Modulation of caudate activity by action contingency. Neuron 41, 281-292.

Tzschentke, T.M., 2000. The medial prefrontal cortex as part of the brain reward system. Amino Acids 19, 1438-2199.
Williams, Z.M., Eskandar, E.N., 2006. Selective recruitment of associative learning by microstimulation of the anterior caudate. Nat. Neurosci. 9, 562-568.

Wise, R.A., 2005. Forebrain substrates of reward and motivation. J. Compar. Neurol. 493, 115-121.

Yamaguchi, S., Kuhlman, D.M., Sugimori, S., 1995. Personality correlates of allocentric tendencies in individualist and collectivist cultures. J. Cross-Cult. Psychol. 26, 658-672. 